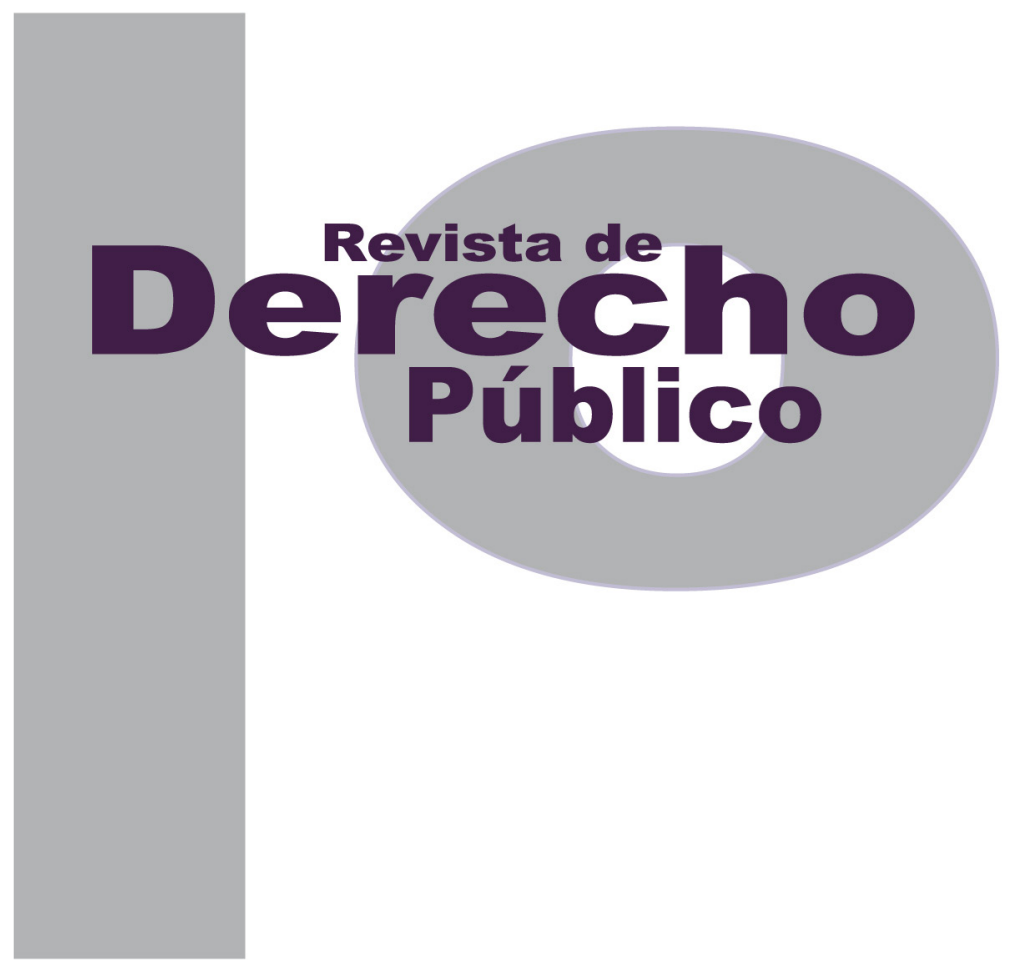

INTERVENCIONISMO HUMANITARIO POSCONFLICTO. DEL SISTEMA DE SEGURIDAD DE NACIONES UNIDAS A LAS ADMINISTRACIONES INTERNACIONALES TRANSITORIAS

ANA MARÍA JARA GÓMEZ

Artículo de reflexión

DOI: http://dx.doi.org/10.15425/redepub.36.2016.07

Universidad de los Andes

Facultad de Derecho

Rev. derecho publico No. 36

enero - junio de 2016. e-ISSN 1909-7778 


\title{
Intervencionismo humanitario posconflicto. Del Sistema de Seguridad de Naciones Unidas a las administraciones internacionales transitorias
}

\section{Resumen}

El sistema de seguridad colectiva de Naciones Unidas ha experimentado grandes transformaciones desde sus comienzos. Las administraciones internacionales transitorias suelen describirse como el último paso evolutivo de las operaciones de paz de Naciones Unidas. Estas incluyen un componente civil y llevan a cabo funciones de construcción del Estado, como el establecimiento o consolidación de las instituciones en situaciones de posguerra. Este artículo pretende realizar un análisis del recorrido y las vicisitudes de las operaciones de paz, concediendo atención especial a aquellas que sustituyen al Estado mismo.

Palabras clave: seguridad colectiva, operaciones de mantenimiento de la paz, administraciones internacionales transitorias, construcción del Estado.

\section{Post-conflict humanitarian interventionism. From the United Nations Security System to tran- sitory international administrations}

\begin{abstract}
The collective security system of the United Nations has had major changes since its beginning. Transitory international administrations are usually shown as the last step in the evolution of UN peace operations. They include a civil component and have State-building functions, such as the establishment or consolidation of institutions in post-war contexts. This papers aims to provide an overview of peace operations with an especial emphasis on those that substitute the State.
\end{abstract}

Key words: Collective security; peace operations; transitory international administrations; State-building.

\section{Intervencionismo humanitário pós-conflito. Do Sistema de Segurança das Nações Unidas às administrações internacionais transitórias}

\section{Resumo}

O sistema de segurança coletivo das Nações Unidas tem experimentado grandes transformações desde seus primórdios. As administrações internacionais transitórias costumam se descrever como o último passo evolutivo das operações de paz das Nações Unidas. Estas incluem um componente civil e realizam funções de construção do Estado, como o estabelecimento ou consolidação das instituições em situações de pós-guerra. Este artigo pretende realizar uma análise do percurso e as vicissitudes das operações de paz, concedendo especial atenção àquelas que substituem ao próprio Estado.

Palavras-chave: segurança coletiva, operações de manutenção da paz, administrações internacionais transitórias, construção do Estado. 


\title{
Intervencionismo humanitario posconflicto. Del Sistema de Seguridad de Naciones Unidas a las administraciones internacionales transitorias*
}

\author{
ANA MARÍA JARA GÓMEZ**
}

\begin{abstract}
SUMARIO
Introducción - I. ASPECTOS GENERALES DEL SISTEMA DE SEGURIDAD DE NACIONES UNIDAS - II. LAS OPERACIONES DE MANTENIMIENTO DE LA PAZ - III. EVOLUCIÓN DEL MANTENIMIENTO DE LA PAZ TRAS LA GUERRA FRÍA - IV. LOS DESAFÍOS SURGIDOS EN LOS AÑOS NOVENTA - V. LAS ADMINISTRACIONES INTERNACIONALES TRANSITORIAS - VI. “¿NUEVOS PROTECTORADOS?" LAS OPERACIONES DE PAZ EN LA ANTIGUA YUGOSLAVIA - A. La Oficina del Alto Representante en Bosnia Herzegovina - B. La Administración de Naciones Unidas en Kosovo - VII. EL CASO DE TIMOR ORIENTAL - VIII. REFLEXIONES FINALES - Referencias.
\end{abstract}

* Cómo citar este artículo: Jara Gómez, A. M. (Junio, 2016). Intervencionismo humanitario posconflicto. Del Sistema de Seguridad de Naciones Unidas a las administraciones internacionales transitorias. Revista de Derecho Público, (36). Universidad de los Andes (Colombia). http://dx.doi.org/10.15425/redepub.36.2016.07

** Doctora en Derecho por la Universidad de Granada; investigadora del grupo de investigación "Derechos Fundamentales, Andalucía y CE"; LLMeur (Magistra Legum Europae) en Derecho Europeo e Internacional por la Universidad de Bremen (Alemania). Correo: ajara6@ugr.es 


\section{Introducción}

El concepto de intervención humanitaria se encuentra rodeado de cierta ambigüedad dado que el sistema internacional se erige sobre la base de la soberanía estatal, y a pesar de que la globalización ha dificultado el ejercicio de esta por parte de los gobiernos, no ha hecho sino mantener intactas, incluso reforzar, las fronteras. Puede argüirse que la sociedad internacional, a partir de 1945, se construyó sobre el principio de soberanía y también sobre sus excepciones. Se pretende, a lo largo de este artículo, estudiar la trayectoria de las intervenciones humanitarias que se producen tras un conflicto armado, sus fundamentos jurídicos y algunas de sus consecuencias sociopolíticas.

Se explora inicialmente el sistema de seguridad de Naciones Unidas para posteriormente realizar un pormenorizado análisis de la génesis y desarrollo de las operaciones de mantenimiento de la paz. La segunda mitad de este trabajo está centrada en aquellas operaciones que han afectado a la soberanía del Estado, resultando en verdaderas administraciones estatales. La dimensión y la resolución de estas operaciones obligan a reabrir la cuestión sobre el lugar que deben ocupar las intervenciones humanitarias en la sociedad y el derecho internacional, y el alcance exacto del principio de soberanía.

\section{ASPECTOS GENERALES DEL SISTEMA DE SEGURIDAD DE NACIONES UNIDAS}

El principal propósito de la Organización de Naciones Unidas (ONU) es el mantenimiento de la paz y la seguridad internacionales, según lo manifiesta su Carta en el artículo 1.1. Este artículo, junto al preámbulo de la Carta, y los principios contenidos en los arts. 2.3, 2.4 y 2.5 completan la descripción de Naciones Unidas como un sistema de seguridad colectiva que prohíbe la amenaza o el uso de la fuerza. ${ }^{1}$

Los mecanismos de aplicación del sistema de seguridad de la ONU se encuentran en los capítulos VI, VII y VIII, que conceden un papel muy significativo al Consejo de Seguridad. El capítulo VI (arts. 33 a 38) sobre arreglo pacífico de controversias, se caracteriza por su flexibilidad y también por su complejidad. Según los artículos 33 y 37.1 los Estados deben primero acudir a los medios de arreglo pacífico antes de someter una controversia al Consejo de Seguridad; el artículo 33 enumera la negociación, la investigación, la mediación, la conciliación, el arbitraje, el arreglo judicial, el recurso a organismos o acuerdos regionales $u$ otros medios pacíficos de su elección, los buenos oficios y los mecanismos de alerta temprana, que son de uso común aunque no aparezcan en este artículo expresamente. Por otro lado, y según el artículo 35 los Estados pueden, en cualquier

1. En general pueden verse: Vaughan Lowe, Adam Roberts, Jennifer Welsh y Dominik Zaum (eds.), The United Nations Security Council and War, Oxford University Press, 2008 y Thomas George Weiss, Kelly-Kate Pease, David P. Forsythe y Roger A Coate, The United Nations and Changing World Politics, Westview Press, (6 ${ }^{\mathrm{a}}$ ed.), Colorado, 2009. 
momento, someter una controversia al Consejo sin agotar los cauces previos.

El sistema de Naciones Unidas, en el capítulo VIII de la Carta (arts. 52 a 54), prevé también la solución pacífica de conflictos en el contexto de un marco regional. Según el art. 52.2 los miembros de la Organización que pertenezcan a agencias o sean parte de acuerdos regionales deben intentar el arreglo pacífico de sus disputas a ese nivel, antes de acudir al Consejo de Seguridad.

El funcionamiento de los mecanismos de seguridad colectiva, término que no aparece como tal en la Carta, se encuentra en el capítulo VII (arts. 39 a 51) que pone de manifiesto la voluntad de la Organización de ejercer una acción decidida sobre los conflictos que pueden amenazar o poner en peligro la paz y seguridad internacionales y, con este fin, prevé la aplicación de medidas colectivas para mantenerlas. En el marco de este sistema "el Consejo de Seguridad determinará la existencia de toda amenaza a la paz, quebrantamiento de la paz o acto de agresión y hará recomendaciones o decidirá qué medidas serán tomadas de conformidad con los Artículos 41 y 42" (art. 39). capítulo contempla el establecimiento de medidas provisionales para evitar que un conflicto se extienda (art. 40), la aplicación de sanciones que no conlleven el uso de la fuerza (art. 41) y medidas que sí comporten dicho uso (art. 42). La Carta previó en los arts. 43.1 y 44 que los Estados pusieran a disposición del Consejo de Seguridad sus fuerzas armadas y dispuso la creación del Comité de Estado Mayor (arts. 46 y 47) para asistirle en cuestiones militares. Pero las posibilidades previstas en estos artículos no se han materializado, y aunque el Comité se ha reunido periódicamente, no ha tomado decisiones importantes desde finales de los años cuarenta (De Wet y Wood, 2011, p. 44).

Naciones Unidas se vio forzada a encontrar una solución alternativa, que consistía en conceder autorización a los Estados u organizaciones regionales para que llevaran a cabo medidas militares en su nombre. ${ }^{2}$ Dentro de este innovador sistema los Estados mantienen su derecho a la legítima defensa, pero en cualquier caso de uso de este derecho deben informar de inmediato al Consejo de Seguridad que podrá poner en marcha cualquier acción que estime necesaria para restaurar la paz (Gray, 2008, p. 87). Cuando el Consejo de Seguridad autoriza a los Estados para emprender acciones en su nombre no suele hacerlo especificando los artículos de la Carta en que se apoya, sino que

2. Este modelo de autorización se usó por primera vez durante la guerra de Corea, en la Resolución del Consejo de Seguridad 82 (1950) de 25 de junio de 1950. La vuelta de la Unión Soviética al Consejo de Seguridad impidió que fuera utilizado durante el periodo de la Guerra Fría; la única excepción fue la Resolución 221 (1966) de 9 de abril de 1966 adoptada para reforzar el embargo de petróleo contra Rodesia del Sur (actual Zimbabue). El modelo resurgió con la Resolución 678 (1990) de 29 de noviembre de 1990, adoptada tras la invasión iraquí de Kuwait. Actualmente el concepto de autorización está bien establecido como práctica regular del Consejo de Seguridad y fue reconocido por el Tribunal Europeo de Derechos Humanos en el caso Behrami y Behrami contra Francia (ECHR -Grand Chamber- Application Number 71412/01. 22 BHRC 477; (2007) 45 EHRR SE10). 
autoriza la utilización de los medios o medidas necesarias tras hacer referencia a que actúa bajo el capítulo VII. ${ }^{3}$

Es obvio que la responsabilidad primordial del mantenimiento de la paz es del Consejo de Seguridad. El papel de la Asamblea General, conforme a los arts. 11 y 12 de la Carta, es muy limitado a este respecto. Sin embargo, tras la ineficacia mostrada por el Consejo de Seguridad en el conflicto de Corea, ${ }^{4}$ la Asamblea General amplió los poderes que le otorga la Carta, pudiendo intervenir en casos de amenaza a la paz o agresión, de conformidad con la Resolución 377 (V), Ilamada Unión pro Paz. ${ }^{5}$

Unión pro Paz constituyó un intento de equilibrar los poderes del Consejo de Seguridad y la Asamblea General, en un momento en que el Consejo de Seguridad estaba bloqueado por continuos vetos soviéticos y la Asamblea General podía garantizar una mayoría a favor de Occidente. Ha sido invocada en diversas oca- siones, la última de ellas en abril de 1997 para abordar la situación de Jerusalén oriental y los territorios ocupados, pero a pesar de abrir la puerta a la Asamblea General para implicarse en los asuntos relacionados con la paz y la seguridad, su eficacia en este aspecto ha sido escasa.

\section{LAS OPERACIONES DE MANTENIMIENTO DE LA PAZ}

Al girar el sistema estructurado en la Carta sobre la responsabilidad primordial del Consejo de Seguridad, en el que los intereses de los miembros permanentes se protegen a través del derecho de veto, quedó patente que la eficacia real del capítulo VII dependía de la unanimidad de esos miembros. Durante el periodo de la Guerra Fría todas y cada una de las acciones del Consejo de Seguridad referentes al sistema de seguridad colectiva fueron objeto de veto.

3. Como ejemplos de esta práctica pueden mencionarse las resoluciones del Consejo de Seguridad 678 de 29 de noviembre de 1990, respecto a Irak; Res. 929 de 22 de junio 1994, respecto a Ruanda; Res. 1080 de 15 de noviembre de 1996, respecto a la República Democrática del Congo; Res. 1272 de 25 de octubre de 1999, respecto a Timor Oriental; Res. 1386 de 20 de diciembre de 2001, respecto a Afganistán; y Res. 1546 de 8 de junio de 2004, respecto a la invasión de Irak.

4. Cuando Estados Unidos respondió a la invasión llevada a cabo por Corea del Norte, Naciones Unidas respondió a su vez a la reacción estadounidense. La iniciativa fue, por tanto, norteamericana, y tomada durante la Guerra Fría, pidiendo el apoyo 'moral' de la Organización para un recurso a la fuerza que se hubiese producido en todo caso. Los actores aprovecharon que la Unión Soviética estaba ausente del Consejo de Seguridad en protesta por un asunto diferente. Las resoluciones del Consejo de Seguridad respecto a Corea (Res. 82 de 25 de junio de 1950, Res. 83 de 27 de junio de 1950, Res. 84 de 7 de julio de 1950 y Res. 85 de 31 de julio de 1950) no aplican el aparato coactivo de los arts. 41 y 42 de la Carta, que era lo indicado tal y como señala Hans Kelsen (1951), dado que el órgano consideraba necesario el uso de la fuerza. El Consejo de Seguridad, en su Resolución 83, recomienda que los miembros de la oNU presten a la República de Corea la ayuda necesaria para repeler el ataque de las fuerzas norcoreanas, cuya existencia había determinado en la Resolución previa. Según Kelsen (1951), el Consejo de Seguridad se limita a recomendar a los miembros que ejerzan un derecho de autodefensa colectiva en caso de ataque armado, tal como prevé el art. 51 de la Carta.

5. Resolución de la Asamblea General de Naciones Unidas 377 (V), de 3 de noviembre de 1950. 
Es necesario, además, observar que los mecanismos previstos en el capítulo VII no estaban diseñados para resolver conflictos intraestatales sino conflictos entre Estados. Sin embargo, desde la adopción de la Carta, y más frecuentemente desde el fin de la Guerra Fría en el año 1991, los primeros eran abrumadoramente más numerosos que los segundos, y esto tuvo como resultado la necesidad de aplicación de las medidas coercitivas del capítulo VII también a conflictos internos. El sistema resulta inoperante debido a la combinación entre parálisis del Consejo de Seguridad y una interpretación estática e inflexible del principio de soberanía estatal.

La ONU no pudo sino improvisar vías alternativas que permitieran su participación en el mantenimiento de la paz y la seguridad sin implicar la aplicación de su propia Carta. Una de estas vías, la más importante, tuvo como base la Resolución Unión pro Paz, ya mencionada. El documento, aunque no logró sus objetivos de equilibrio de poder entre Consejo de Seguridad y Asamblea General, sí tuvo el efecto de ofrecer impulso al desarrollo de los principios de una práctica de Naciones Unidas que se convertiría en el símbolo más visible de su papel en la paz y seguridad internacionales: las operaciones para el mantenimiento de la paz (OMP).
La crisis del Canal de Suez dio lugar a la primera reunión extraordinaria de la Asamblea General que creó la Fuerza de Urgencia de las Naciones Unidas (UNEF I), con el objetivo de supervisar el fin de las hostilidades, la retirada de las tropas francesas, británicas e israelíes e interponerse posteriormente entre estas últimas y las fuerzas armadas egipcias. Para la creación de la UNEF I la Asamblea General solicitó al Secretario General un informe sobre cómo debería realizarse el establecimiento de la fuerza. ${ }^{6} \mathrm{El}$ informe que realiza Dag Hammarskjold (1961) acuña el término Operaciones para el Mantenimiento de la Paz y señala los principios de su organización y funcionamiento: Naciones Unidas es quien nombra al jefe de la fuerza, que responderá ante la Organización; debe ser de carácter temporal y no tratar de influir sobre el conflicto; necesita el consentimiento del Estado receptor para desplegarse en su territorio; no se trata de una fuerza militar de combate con el control del territorio; su función se centra en garantizar el alto el fuego y verificar el cumplimiento de las resoluciones; los salarios y equipos de las fuerzas serán financiados por sus Estados de origen pero la ONU cubrirá el resto de los gastos. ${ }^{7}$

El Tribunal Internacional de Justicia contribuyó a resolver la cuestión financiera derivada de la

6. Resolución de la Asamblea General 998 (ES I) de 4 de noviembre de 1956. Entre 1948 y 1987 la única fuerza que, como UNEF I, fue autorizada por la Asamblea General fue UNSF (United Nations Security Force in West New Guinea), creada para asistir a la administración temporal fiduciaria de Naciones Unidas en el territorio de Nueva Guinea Occidental que tenía como cometido prepararlo para ser transferido a Indonesia por las autoridades de los Países Bajos. La Resolución de la Asamblea General 1752 (XVII) autoriza al Secretario General a llevar a cabo la labor que le encomienda el art. 2 del Acuerdo de Nueva York entre Indonesia y Holanda, firmado el 15 de agosto de 1962, es decir, a proceder al establecimiento de UNSF.

7. Informe del Secretario General de 6 de noviembre de 1956, un Doc. A/3302. 
negativa de algunos Estados miembros a contribuir con los gastos de las operaciones, dictaminando que estos debían considerarse gastos de organización, pudiendo exigirse a todos los miembros de la ONU. El Tribunal señaló también que las OMP no podían considerarse medidas coercitivas del capítulo VII de la Carta, y por tanto podían ser creadas no solo por el Consejo de Seguridad, sino también por la Asamblea General y por el Secretario General. ${ }^{8}$ Sin embargo, ciertas cuestiones políticas quedaban abiertas y fue necesaria la creación de un Comité Especial de Operaciones para el Mantenimiento de la Paz, ${ }^{9}$ que alcanzó un consenso que, además de incluir los principios rectores de las OMP, logró decidir que el Consejo de Seguridad detentaría la autoridad para establecer, dirigir y controlar las operaciones; el Secretario General sería el comandante en jefe de las operaciones; y las fuerzas serían proporcionadas por Estados seleccionados por el Secretario General. ${ }^{10}$

Los debates de la Asamblea General respecto de la primera operación y de la posteriormente desplegada en Congo en 1960 (ONUC) sentaron las bases del mantenimiento de la paz de Naciones Unidas, cuyas operaciones debían: i) disponer de la confianza del Consejo de Seguridad en todo momento; ii) contar con la cooperación de las partes concernidas; iii) funcionar como unidades militares integradas y eficientes; iv) ser imparciales en el conflicto; y v) no recurrir a la fuerza salvo en los casos de legítima defensa (Cardona Llorens 2003, pp. 778 y ss.). Todas las operaciones excepto dos, de un total de trece desplegadas hasta 1987, fueron autorizadas por el Consejo de Seguridad. El Consejo de Seguridad no se acogió al capítulo VI ni pudo acomodarlas en el VII; tal y como el Secretario Hammarskjold lo describió, las OMP pertenecían a un fingido Capítulo seis y medio, representando el ajuste funcional de la Organización a un sistema internacional que giraba en torno a la rivalidad y el miedo a la guerra absoluta (Hammarskjöld, 1961).

Ya en los primeros años sesenta se habían establecido varias operaciones en Yemen, Chipre, República Dominicana e India y Pakistán, pero en 1967 las OMP entraron en crisis debido a los acontecimientos que siguieron a la retirada de UNEF I de territorio egipcio. Los hechos tuvieron lugar cuando Egipto solicitó al Secretario General de la ONU que replegara la misión y este lo hizo sin previa consulta al Consejo de Seguridad o a la Asamblea General, considerando que ya no se daba la condición imprescindible de contar con el consentimiento del Estado donde estaba desplegada la operación. Solo unos días más tarde se desató la Guerra de los Seis Días entre Israel y los países árabes. Tras este episodio, en el año 1972, la India solicitó la misma acción con respecto a la operación desplegada en el

8. Dictamen del Tribunal Internacional de Justicia sobre Ciertos Gastos de las Naciones Unidas, de 20 de julio de 1962.

9. Resolución de la Asamblea General de Naciones Unidas 2006 (XIX), de 18 de febrero de 1965.

10. Informe del Comité Especial de Operaciones para el Mantenimiento de la Paz, Doc. A/9827. 
estado de Jammu y Cachemira (Grupo de Observadores Militares de las Naciones Unidas en la India y Pakistán -UNMOGIP-) y, en un sustancial giro, el Secretario General declaró que esa era una decisión que debía tomar el Consejo de Seguridad.

Antes del fin de la Guerra Fría, las operaciones que Naciones Unidas puso en marcha eran primordialmente militares y tenían como objetivo ayudar a controlar los conflictos que amenazaban la paz internacional mientras se trataba de lograr soluciones políticas duraderas. Asumían el rol de un tercero imparcial, permitiendo además la observación de procesos electorales, el establecimiento y mantenimiento del alto el fuego y la fijación de una zona destinada a separar a las partes beligerantes. La idea principal era que la presencia física de una fuerza multinacional, neutral e imparcial tuviera un carácter disuasorio sobre aquellos que deseaban seguir la lucha armada. El mantenimiento de la paz había reemplazado a la idea de imposición coercitiva de la paz.

Ninguna de estas OMP estaba destinada a la gobernanza o la administración de territorios. El art. 77 de la Carta contempla el régimen internacional de administración fiduciaria, que se aplicó principalmente a aquellos territorios que estaban bajo el mandato de la Sociedad de Naciones porque habían sido separados de estados enemigos tras la segunda guerra mundial; o bien otros que eran sometidos vo- luntariamente a este régimen "por los Estados responsables de su administración”. En cualquier caso, el papel de la ONU respecto a los territorios fideicometidos quedaba circunscrito a un acuerdo con los Estados afectados y lo usual era que se limitase a una supervisión muy general mientras la gobernanza quedaba en manos del estado fideicomisario. ${ }^{11}$

\section{EVOLUCIÓN DEL MANTENIMIENTO DE LA PAZ TRAS LA GUERRA FRÍA}

Al finalizar la Guerra Fría las operaciones de paz vivieron un relanzamiento $y$, sobre todo, evolucionaron a pasos agigantados asumiendo funciones enteramente nuevas. El Consejo de Seguridad autorizó numerosas operaciones entre 1989 y 1993 en países que acababan de sufrir conflictos civiles: Namibia, Nicaragua, Angola, Camboya, El Salvador, Mozambique, Liberia, Somalia, Yugoslavia, Georgia y Ruanda (Cardona Llorens, 2003, p. 778). Estas misiones distaban mucho de aquellas operaciones de mantenimiento de la paz tradicionales que habían constituido la principal función de las Naciones Unidas respecto a la seguridad internacional durante el periodo de bloques. El mantenimiento de la paz incluía ahora la implementación efectiva de acuerdos de paz, que a su vez llevaban consigo elementos humanitarios, políticos y económicos que se añadían a las tareas previas de vigilancia de la cesación del fuego.

11. La excepción fue UNTEA, la Administración Internacional Transitoria en Nueva Guinea Occidental. Para un análisis detallado del sistema de fideicomiso véase, entre otros, George Thullen (1994). 
En la atmósfera expansionista y satisfecha que rodeaba a las OMP en 1992, el Secretario General Boutros-Ghali publicó su Programa de Paz, que abría las puertas a la creación de OMP sin consentimiento de las partes afectadas por el conflicto y a la posibilidad de recurrir a la fuerza más allá de la legítima defensa. ${ }^{12}$ Para preservar la paz y la seguridad, el Programa hacía hincapié en la posibilidad de adoptar medidas preventivas que incluyeran el despliegue de tropas de mantenimiento de la paz. Hasta ahora UNPREDEP, ${ }^{13}$ la operación desplegada en Macedonia es el único caso de operación preventiva. ${ }^{14}$ A partir de este momento ya no cabe hablar exclusivamente del mantenimiento de la paz, las actuaciones de Naciones Unidas van a incluir un amplio espectro de actividades y a menudo la responsabilidad va a compartirse con otros actores internacionales, organizaciones regionales, instituciones financieras, agencias de desarrollo e incluso ONG. El Programa de Paz creó formalmente el Departamento de Operaciones para el Mantenimiento de la Paz (DPKO), destinado a ser la guía política y ejecutiva de las operaciones y del Secretario General y los Estados Miembros con respecto a ellas.

Además de mantenimiento de la paz (Peacekeeping), definido como técnica para preservar la paz una vez cesadas las hostilidades y para asistir e implementar acuerdos entre las partes, se introducen nuevos conceptos que evolucionan desde el primario formato militar de observación del alto el fuego y la separación de fuerzas a otros modelos más complejos que incluyen elementos policiales y civiles. Comienzan a usarse nuevos términos: pacificación (Peacemaking), que incluye medidas de aproximación a conflictos en curso y suele llevar aparejadas acciones diplomáticas que acerquen a las partes a un acuerdo. El Secretario General puede ejercer sus buenos oficios para facilitar la resolución del conflicto, bien por propia iniciativa, bien a instancias del Consejo de Seguridad o la Asamblea General. Las labores de pacificación pueden ser llevadas a cabo también por grupos no oficiales o personalidades de reconocido prestigio que trabajen de modo independiente; construcción de la paz (Peacebuilding), que abarca las medidas destinadas a reducir el riesgo de comenzar o renovar un conflicto a través del refuerzo de las capacidades nacionales para la gestión de conflictos a todos los niveles y de construir los cimientos para la sostenibilidad de la paz y el desarrollo. La construcción de la paz es un proceso complejo y a largo plazo que implica crear las condiciones necesarias para una estabilidad duradera, funciona atacando las causas estructurales de un

12. Informe del Secretario General "Un programa de Paz. Diplomacia preventiva, establecimiento de la paz y mantenimiento de la paz", (A/47/277 y S/24111) de 30 de junio de 1992.

13. United Nations Preventive Deployment Force (Fuerza de Despliegue Preventivo de las Naciones Unidas).

14. Fue establecida por Resolución del Consejo de Seguridad 795, de 11 de diciembre de 1992 y en principio su mandato estaba restringido a la vigilancia de las fronteras de Macedonia con Yugoslavia y Albania. Más tarde se extendió al mantenimiento de la paz y estabilidad (a través de Resolución del Consejo de Seguridad 908, de 31 de marzo de 1994), un mandato suficientemente flexible como para que el correspondiente Representante Especial del Secretario General interpretara que permitía abordar problemas internos del Estado como las tensiones entre grupos étnicos. 
conflicto violento de modo integral y requiere incidir en cuestiones básicas que afectan tanto al Estado como a la sociedad; por último, la consolidación (o imposición) de la paz (Peace Enforcement) implica la aplicación de medidas coercitivas, con autorización del Consejo de Seguridad, que incluyen el uso de la fuerza. Son medidas que se consideran necesarias para restaurar la paz y la seguridad internacionales una vez que el Consejo ha determinado la existencia de una amenaza o quiebra de la paz, o un acto de agresión. El Consejo de Seguridad puede, si lo considera apropiado, utilizar agencias regionales para llevar a cabo, bajo su autoridad, esta clase de acciones. $^{15}$

Cuando las OMP recibieron el Premio Nobel de la Paz en 1988 servían en ellas unas 10.000 personas procedentes de 35 países, y su coste anual se encontraba alrededor de los $230 \mathrm{mi}-$ Ilones de dólares norteamericanos. En su momento álgido, a mediados de 1994, costaban unos 4 billones y tenían más de 87.000 personas empleadas en 17 operaciones (Thakur y Schnabel, 2001, p. 11).

\section{LOS DESAFÍOS SURGIDOS EN LOS AÑOS NOVENTA}

A mediados de los noventa aparece de nuevo la crisis en el sistema de operaciones de paz de Naciones Unidas. Las misiones habían sido breves, limitadas, y se habían centrado en rápidas reformas económicas y políticas para consolidar la paz. En algunos casos los oficiales de la ONU se apresuraron a celebrar elecciones tras el conflicto, declararon el éxito obtenido y abandonaron el lugar. Este método, que Paris y Sisk (2007) llaman rápido y sucio, supuso un estrepitoso fracaso. Pueden citarse algunos casos significativos: en Angola, donde las elecciones fueron el catalizador de nuevas explosiones de violencia; en Ruanda, donde se confió en la voluntad de las partes para que cumplieran el acuerdo de paz y tuvo lugar un genocidio; y en Camboya y Liberia, donde las elecciones dieron como resultado una democracia superficial y el rápido retorno al autoritarismo, y, en el caso de Liberia, una nueva guerra (pp. 2-3).

Esta lista de fracasos llevó al Secretario General de la ONU a presentar el Suplemento de un Programa de Paz, documento en que revisaba las recomendaciones realizadas en 1992 y volvía a los principios de consentimiento del Estado receptor y abstención del uso de la fuerza salvo en casos de legítima defensa. ${ }^{16}$ El documento sentaba también los principios sobre los que debían constituirse las operaciones en que Naciones Unidas colaboraba con acuerdos o agencias regionales, las llamadas

15. Estas definiciones son proporcionadas por el DPKO en su llamada Doctrina Capstone, que incluye también las actuaciones preventivas: United Nations Department of Peacekeeping Operations, Department of Field Support United Nations Peacekeeping Operations. Principles and Guidelines, 2008, pp. 17-18. Disponible en: http://pbpu.unlb.org/pbps/Library/Capstone_Doctrine_ENG.pdf.

16. Supplement to An Agenda for Peace: Position Paper of the Secretary General on the Occasion of the Fiftieth Anniversary of the United Nations, Un Doc. A/50/60-S/1995/1, de 3 de enero de 1995. 
operaciones complejas, en las que es necesario un mandato flexible que pueda incluir el carácter diverso tanto de las operaciones como de las organizaciones implicadas. La primacía de Naciones Unidas debe ser siempre respetada y las competencias distribuidas claramente entre esta y las organizaciones regionales para evitar el solapamiento y las posibles divergencias. Bajo los parámetros del Suplemento se pusieron en marcha operaciones como las de Angola, Camboya, El Salvador, Mozambique y Namibia, que fueron desplegadas para ayudar en la implementación de los acuerdos de paz, estabilizar la situación, reorganizar la policía y el ejército, asistir en la celebración de elecciones y en la construcción de instituciones democráticas.

En la evolución de las OMP resulta crucial el fenómeno que proliferó al hilo de la crisis de mediados de los noventa: la autorización del Consejo de Seguridad para que el mantenimiento de la paz fuera llevado a cabo por fuerzas multinacionales ajenas a la ONU. Estas fuerzas son consideradas operaciones de paz, con un mandato autorizado de la ONU, pero con un mando internacional al margen de Naciones Unidas. Estas misiones cuentan siempre con el consentimiento del Estado al que se destinan y autorización para el uso de la fuerza. Estas misiones no son jurídicamente órganos del Consejo de Seguridad, ni se consideran parte de la estructura de Naciones Unidas, que simplemente las autoriza. Cardona Llorens (2003) considera que esta práctica supone una vuelta a los precedentes de los años cuarenta y cincuenta y, en lugar de profundizar en el sistema de seguridad colectiva, se opta por dar el paso de desintegrar las operaciones una vez que se había logrado que estuvieran integradas dentro de Naciones Unidas. Añade este autor que este es un proceso no solo de externalización del mantenimiento de la paz, sino de privatización, es decir, de asunción por los Estados de funciones propias de las Naciones Unidas (pp. 796 y ss.).

La Carta de Naciones Unidas prevé que el Consejo de Seguridad autorice a Acuerdos o Agencias regionales para realizar operaciones que conlleven medidas coercitivas. La autorización, que no exigencia, para el uso de la fuerza en virtud del capítulo VIII representa esencialmente la delegación por parte del Consejo de Seguridad de los poderes que le confiere el capítuIo VII. El capítulo VIII no concede al Consejo de Seguridad poderes adicionales para mantener la paz, y el art. 53.1 de la Carta solo le da la competencia para ceder los poderes del capítulo VII a los citados organismos regionales. El hecho de que tales poderes sean ejercidos a través de mecanismos ajenos no altera la posición jurídica del Consejo de Seguridad, que debe mantener su autoridad y su control sobre la acción que se ejerza. El propio artículo 53 establece expresamente que la delegación está condicionada a que la operación permanezca bajo la autoridad del Consejo de Seguridad (Saaroshi, 2008, p. 228). Cardona Llorens (2003) considera que este es un proceso no solo de externalización del mantenimiento de la paz, sino de privatización, es decir, de asunción por los Estados de funciones propias de las Naciones Unidas (p. 796). 
A pesar de que existen innumerables clasificaciones de las OMP, conscientemente he decidido exponerlas aquí de modo general. El motivo es que no parece posible, a la vista de la evolución de la práctica del mantenimiento de la paz, llegar a una conclusión distinta de que Naciones Unidas ha puesto en marcha cada operación en respuesta a hechos de muy diversa índole, en un entorno mundial y local también muy diferente, para encontrarse en cada una de ellas con acontecimientos impredecibles que demandaban acciones distintas y modelos distintos de operación de paz. Es decir, casi cada OMP, y muy especialmente las que ejercen la gobernanza sobre el territorio, puede ser considerada una nueva generación en sí misma a pesar de que, como señala Simon Chesterman (2005), la terminología sugiere engañosamente un desarrollo lineal del mantenimiento de la paz (p. 341).

En todo caso, de las páginas precedentes pueden deducirse, a grandes rasgos, las características de al menos tres generaciones de OMP. En primer lugar, las llamadas operaciones tradicionales, sin uso ni amenaza de la fuerza, imparciales y establecidas sobre la base del consentimiento de los implicados. Estas misiones son sucedidas por una segunda generación de mantenimiento de la paz multidimensional, que incluye, según algunos autores, la operación desplegada en el Congo entre 1960 y 1964 (Chesterman, 2004, p. 238). A través de estas operaciones, la ONU se ve envuelta en conflictos internos a través de procesos multidimensionales que incluyen actividades, añadidas a las tradicionales, como la separación de combatientes, el desarme de fuerzas irregulares o paramilitares y en ocasiones su transformación en un ejército nacional unificado, tareas de reinserción en la sociedad civil y establecimiento de sistemas policiales.

La tercera generación corresponde a las operaciones que no se limitan a mantener la paz sino también a la consolidación/imposición de la paz y operan con mandato del Consejo de Seguridad amparado en el capítulo VII de la Carta. Esta tercera generación surge apenas seis meses después de la segunda, en marzo de 1993, con UNOSOM II en Somalia, la primera misión que el Consejo de Seguridad establece amparándose explícitamente en el capítulo vII de la Carta.

Podría decirse que este tipo de operaciones, se las considere o no tercera generación, fueron precipitadas por el resurgimiento de animosidades que durante la Guerra Fría habían sido suprimidas, que no solucionadas, y que llevaron a conflictos caracterizados por la vulneración masiva de los derechos humanos amparada en condiciones de anarquía. Se despliegan estas operaciones no para mantener la paz, que puede no existir, sino para responder a un fuerte deseo de la comunidad internacional de apoyar los esfuerzos de asistencia humanitaria hasta que se den las condiciones para negociar la solución del conflicto. El consentimiento de las partes puede estar ausente porque la autoridad haya colapsado o resulte poco significativo porque existan numerosos grupos reivindicando dicha autoridad (Malan, 1998, p. 3).

De este modo, a finales de la década de los noventa y tras un paréntesis en que solo se reno- 
varon misiones ya existentes, la ONU comenzó a desplegar nuevas OMP acompañadas de mandatos amplios y una vocación que iba más allá del corto plazo y que, como se verá, a menudo incluían tareas de reconstrucción del Estado.

La expansión de las agendas y las responsabilidades de los actores externos, y especialmente de la ONU, en los territorios posconflicto es explicada por Richard Caplan (2005) considerando un número de factores, que incluyen desde la proliferación de conflictos internos en detrimento de aquellos internacionales, la erosión de la soberanía del Estado, hasta la responsabilidad de proteger que recae sobre la comunidad internacional junto a la creciente cooperación dentro del Consejo de Seguridad de la ONU. Antes de UNOSOM II, el Consejo de Seguridad había sufrido el veto sobre resoluciones que se amparaban en el capítulo VII en 279 ocasiones entre 1945 y 1990 (p. 8).

Esta evolución puede leerse en clave de que los actores externos pretenden algo más que finalizar la guerra y establecer la seguridad. Entre los objetivos implícitos o explícitos de las OMP se encuentra ahora firmemente arraigada la democratización.

Las tareas específicas que incluye el proceso democratizador van desde la creación de partidos políticos hasta el apoyo de la prensa libre. Pero estas tareas son llevadas a cabo desde fuera de la sociedad a la que van destinadas.
Las OMP diseñadas para implementar ambiciosos procesos de democratización necesitan recursos civiles, militares y financieros acordes a sus objetivos, y también autoridad legítima y poder político. En numerosas ocasiones la reconstrucción de las estructuras del Estado va de la mano de la asunción de funciones gubernamentales y el control administrativo de un territorio (Roehner, 2010, p. 2). En estos casos la misión de paz se convierte o incluye la administración internacional de un territorio o de un Estado. Entonces el intervencionismo de los actores externos es enorme, puede abarcar de hecho todos los poderes soberanos del Estado.

\section{LAS ADMINISTRACIONES INTERNACIONALES TRANSITORIAS}

En el debate académico actual, las administraciones internacionales suelen describirse como el último paso evolutivo de las OMP de Naciones Unidas, de aquellas llamadas multidimensionales, que incluyen componente civil y llevan a cabo funciones de construcción del Estado como el establecimiento o consolidación de las instituciones en situaciones de posguerra. Esta práctica de Naciones Unidas es difícil de conceptualizar, de hecho cada una de estas operaciones difiere de las demás en muchos aspectos, incluso no todas se han establecido tras un conflicto, algunas han sido un elemento para impulsar un acuerdo de paz y otras se han desplegado durante el conflicto mismo. ${ }^{17}$ El elemen-

17. Algunos ejemplos de despliegue de misiones de paz donde no había paz que mantener son UNPROFOR, UNAMIR y UNOSOM II. 
to diferenciador más importante es el alcance del mandato, que puede ir de la autoridad administrativa parcial a los plenos poderes sin límite fáctico. Los proyectos son diferentes, también su duración, sus objetivos específicos y, significativamente, también cambia la base jurídica que sostiene a cada administración internacional y a la autoridad que la llevará a cabo.

Cuando hablamos de una administración internacional transitoria hablamos de administración directa de territorios por parte de la ONU. El término administración directa se refiere al gobierno de un territorio por parte de una entidad externa con base en la autoridad de las resoluciones del Consejo de Seguridad de Naciones Unidas. Esto tiene que ver principalmente con la aplicabilidad directa de las decisiones tomadas por la entidad sobre el sistema legislativo del territorio afectado.

El siglo XX fue testigo de la proliferación de muy diversas formas de compromiso internacional en áreas que siempre habían sido competencia de los Estados. La implicación de actores internacionales en la administración de territorios es solo una muestra de ello; el Manual de las Naciones Unidas sobre operaciones de mantenimiento de la paz multidimensionales incluye la administración internacional de un territorio como una función más de estas operaciones y afirma que puede exigirse a las operaciones de paz "administrar un territorio por un periodo transitorio y de ese modo que Ileven a cabo funciones que normalmente son responsabilidad de un gobierno". ${ }^{18}$

A pesar de las diferencias mencionadas previamente, las administraciones internacionales transitorias tienen ciertas características comunes: la delegación de la administración por parte del soberano territorial (o, en ausencia de autorización explícita, su ejercicio en beneficio de la población local), donde todos los proyectos constan de una estructura de gestión localizada en el territorio en el que va a operar, referida a toda la administración o a parte de ella; los administradores tienen un carácter dual, por una parte, actúan como autoridades locales y, por otra, como autoridades internacionales $y$, sobre todo, siempre tienen un impacto directo en la vida de la población. En muchos casos sus decisiones tienen efectos irreversibles a largo plazo. En general, las administraciones internacionales transitorias pretenden implementar un objetivo político, la institución de un sistema de gobierno liberal que incluye aspectos económicos, de democratización y que abarca los derechos humanos. A menudo la aplicación directa del derecho internacional es la herramienta más importante para alcanzar dicho objetivo (Koskenmäki, 2005).

El acercamiento al estudio de las administraciones internacionales transitorias ha estado

18. United Nations, Department of Peacekeeping Operations, Peacekeeping Best Practices Unit, Handbook on United Nations Multidimensional Peacekeeping Operations, diciembre de 2003. 
caracterizado por un enfoque que podríamos llamar estanco, en el sentido de que no se realiza un análisis sistemático de los resultados de cada una de las operaciones. Cada experiencia es seguida por la siguiente sin haberse realizado una evaluación de sus resultados, los obstáculos encontrados o sus factores de éxito en la práctica. Naciones Unidas no realiza el análisis y evaluación integral de las misiones de administración de territorios que pone en marcha sino que hace, como mucho, revisiones individuales. Se podría decir que cada una de ellas es un experimento nuevo que no se beneficia de la experiencia de aquellos que lo precedieron, y a menudo se critica la falta de planificación y coherencia de las administraciones internacionales.

El primer ejercicio de envergadura que realizó la ONU en cuanto a gobernanza de territorios comenzó en 1991 con el Acuerdo de París (Acuerdo para el Arreglo Político Integral del Conflicto de Camboya -Agreement on a Comprehensive Political Settlement of the Conflict in Cambodia-), que estableció un Consejo Nacional Supremo compuesto por representantes de las facciones en contienda, que delegaba diversas funciones gubernamentales en las Naciones Unidas para ser ejercidas por UNTAC (Autoridad Provisional de las Naciones Unidas en Camboya, por sus siglas en inglés). Es decir, la misión fue establecida sobre una base contractual y se le confiaron poderes significativos en cuanto a la administración civil, además del control directo de los asuntos exteriores, la defensa nacional, la economía, la seguridad pública y el derecho a llevar a cabo investigaciones sobre la actividad de otros órganos gubernamentales con objeto de determinar si estaban boicoteando el Acuerdo y tomar las medidas correctivas necesarias. La autoridad de UNTAC estaba limitada por la exigencia de seguir los dictados de cualquier posible decisión de consenso entre las facciones representadas en el Consejo, siempre que esta no violara el Acuerdo. Adicionalmente la misión también estaba encargada de llevar a cabo las tareas tradicionales de una OMP. El Representante Especial del Secretario General de esta operación tenía la autoridad de legislar en estas áreas y también en el ámbito electoral. UNTAC tenía la capacidad de revocar cualquier ley que pusiera en peligro los propósitos del Acuerdo de Paz y su impacto legislativo fue considerable (De Wet, 2004, p. 298). El ejercicio directo de los poderes de gobierno se extendía también a cuestiones de ámbito judicial.

El Consejo de Seguridad no autorizó a la UNTAC usando los poderes que le otorga el capítulo VII de la Carta, sino que actuó según su autoridad para hacer recomendaciones a los Estados para el arreglo pacífico de controversias. En consecuencia, el consentimiento de las partes camboyanas era un elemento esencial para que el mandato de la UNTAC tuviera una base jurídica. La explicación que corresponde a esta decisión del Consejo es esencial: la operación de Naciones Unidas en Camboya no tenía ninguna relación con el estatus internacional del país, es decir, la soberanía no era un tema presente que hubiera que abordar en ningún momento, aunque la disputada legitimidad del gobierno de Phnom Penh fue el factor que pro- 
vocó que la ONU interviniese. El hecho de que la soberanía de Camboya no estuviera en cuestión permitió, o más bien, obligó, a que la intervención se realizase al amparo del capítulo vı y que se produjese después de un alto el fuego negociado y un acuerdo de paz (Mayall, 1996, pp. 12-13). Mi opinión es que el hecho de que todas las partes incumplieran el Acuerdo de París, que antes de las elecciones la soberanía camboyana fuera ya simplemente simbólica y que la UNTAC fue incapaz de cumplir muchos de los objetivos de su mandato no le resta valor a la idea de que la ONU está mejor posicionada como pacificadora si actúa bajo la autoridad de las partes en conflicto que cuando trata de imponer su voluntad desde fuera.

Tras Camboya tuvieron lugar, también a principios de los noventa, otras misiones que gozaron de autoridad ejecutiva en lugares como Somalia (UNOSOM II) y Haití (UNMIH), con mayor o menor éxito, pero sin pretensión de ejercer el gobierno sobre el territorio (Berdal y Economides, 2007, p. 21). El contenido político del mandato de UNOSOM II era suficientemente impreciso como para haber dado lugar a la administración directa, además, la intervención tuvo lugar debido a la desintegración de toda forma de gobierno y a la anarquía imperante. Sin embargo el discurso oficial fue en todo momento que el pueblo de Somalia tenía la responsabilidad última en la reconciliación y la reconstrucción de su propio país. La crisis que Naciones Unidas quería abordar en Somalia era una catástrofe humanitaria causada por el colapso de toda autoridad, de hecho Somalia había perdido su soberanía jurídica y práctica.
Pero otorgar a Naciones Unidas la autorización para tomar cualquier medida en pos de crear un entorno suficientemente seguro como para que los propios somalíes pudieran reconstruir su vida política fue, en el mejor de los casos, problemático, y en el peor, un grave error. El Estado colapsó debido a que la población había elevado sus lealtades de clanes y subclanes por encima del orden público, por tanto ¿a quién se iba a imponer el mandato de la misión? UNOSOM II no encontró respuesta a esta pregunta y esto desembocó en la negativa del Consejo de Seguridad a invocar el capítulo VII ante la crisis de Ruanda y a involucrarse seriamente hasta que fue demasiado tarde.

El papel de la soberanía es prácticamente el mismo en las intervenciones que tuvieron lugar en Haití, Sierra Leona y Timor Oriental (Malone y Einsiedel, 2007, p. 169). Haití es el primer caso en que Naciones Unidas interviene para restaurar un gobierno depuesto. El estudio de las misiones en Haití resulta de gran utilidad en cuanto a las peculiaridades de las negociaciones dentro del Consejo de Seguridad, cómo se ejercen los liderazgos, se forman coaliciones y se reparten las cargas. Haití también pone de relieve cómo trabaja Naciones Unidas asociada a una organización regional, la Organización de Estados Americanos y ofrece una visión de cómo Naciones Unidas y el Consejo de Seguridad improvisan acciones en respuesta a actos que no controlan. Es un caso que presenta misiones que resultaron un éxito pero en las cuales “el paciente no se recuperó" (Bull, 2008, p. 22) y de hecho colapsó por completo en 2004 requiriendo nuevas intervenciones, un caso en 
que la principal responsabilidad del fracaso se encuentra en los actores políticos locales.

La misión en Sierra Leona comenzó llevando a cabo tareas básicas de mantenimiento de la ley y el orden y "ciertas funciones gubernamentales menores". Tras la ruptura del Acuerdo de Lomé comenzó a asumir mayores responsabilidades y prestó asistencia en la organización de las elecciones de 2002, emprendió la promoción de derechos humanos, estableció la Comisión para la Verdad y la Reconciliación, reclutó y formó a más de 3500 policías, intentó rehabilitar la infraestructura judicial, desarmar a los excombatientes, trató de frenar el comercio ilegal de diamantes y asistió al retorno voluntario de más de medio millón de desplazados (Bull, 2008, p. 22).

En la misión desplegada en Timor Oriental, sobre la cual profundizaré posteriormente, las Naciones Unidas tenían autoridad para preparar al país para la independencia que se iba a producir el 20 de mayo de 2002, tras un referéndum acordado entre Indonesia y Portugal (como antigua potencia colonial) en que la mayoría de la población optó por la emancipación. En esta ocasión el Consejo de Seguridad dictó una resolución sobre el capítulo VII que confería poderes a UNTAET, ${ }^{19}$ una fuerza de mantenimiento de la paz liderada por Australia para tomar todas las medidas necesarias conducentes a restaurar la seguridad en la isla. A UNTAET la siguió UNMISET, ${ }^{20}$ operación que continuó ejerciendo poderes en áreas importantes hasta el final de su mandato el 20 de mayo de 2005 y fue sustituida por UNOTIL, ${ }^{21}$ que es esencialmente una misión política.

Aunque los casos mencionados han implicado el ejercicio de la autoridad ejecutiva de Naciones Unidas (algunos de ellos con la oposición de las instituciones nacionales) solo las operaciones emprendidas en la segunda mitad de la década de los noventa y posteriormente han llevado consigo que Naciones Unidas se conceda a sí misma una autoridad sin precedentes equiparable a la de un Estado independiente, pero sin muchas de las salvaguardas democráticas que los ciudadanos de un Estado deben tener a su disposición.

\section{VI. “¿NUEVOS PROTECTORADOS?” LAS OPERACIONES DE PAZ EN LA ANTIGUA YUGOSLAVIA}

Ocasionalmente se usa el término protectorado internacional para describir el sistema de gobernanza establecido por la comunidad internacional en Kosovo y también en Bosnia Herzegovina. Esta noción, propia del posco-

19. United Nations Transitional Administration in East Timor (Administración de Transición de las Naciones Unidas para Timor Oriental).

20. United Nations Mission of Support to East Timor (Mision de Apoyo de las Naciones Unidas en Timor Oriental).

21. United Nations Office in Timor-Leste (Oficina de las Naciones Unidas en Timor Oriental). 
Ionialismo y diseñada para aquella situación concreta, no se corresponde por completo con las características de las administraciones interinas en estos territorios. Por definición, un protectorado internacional es una relación legal entre un "Estado protector" y un "Estado protegido", o varios, donde el último cede todo o parte de su control en los asuntos exteriores mientras retiene en gran medida su independencia en asuntos internos. Hasta qué punto el Estado dominante podía inmiscuirse en los temas locales quedaba reflejado en un tratado entre ambos Estados. A pesar de que el término protectorado abarca una gran variedad de relaciones que resultan en diversos grados de dependencia, es, en su sentido original, un término restringido a las relaciones EstadoEstado. Técnicamente ni la misión de la ONU en Kosovo (UNMIK), ni la administración que se estableció en Bosnia Herzegovina pueden calificarse de protectorados (Stahn, 2008, p. 9).

Las operaciones en la antigua Yugoslavia carecían de la ventaja de inicio de una soberanía no disputada. La entonces Comunidad Europea no acompañó el reconocimiento de Croacia y Bosnia Herzegovina con las necesarias condiciones que la hicieran creíble y que impidiesen que los grupos serbios continuaran clamando, y matando, por la Gran Serbia. Aunque escapa claramente a los objetivos de este trabajo, debe mencionarse que resulta una fuente de dificultades el asumir que el otorgamiento de la soberanía se produce en el exterior y no necesita contenido empírico.

El papel de la ONU en la República Federal de Yugoslavia fue inicialmente confuso, debido a que Yugoslavia se vio inmersa en una serie de guerras civiles que se solapaban entre ellas y ninguno de los contendientes parecía preparado para negociar un acuerdo político sin antes intentar mejorar su posición militarmente, de modo que la presencia internacional estaba constantemente sujeta a condiciones. Los cascos azules de la ONU debían, inicialmente, servir de protección para convoyes humanitarios y mantener la seguridad básica de las minorías étnicas. El mandato pasó de estar bajo el capítulo VI a permitir tomar cualquier medida necesaria para su cumplimiento, pero no se acompañó este cambio con los recursos ni la voluntad necesarios (Matheson, 2001, p. 77).

La ruptura de la República Federal de Yugoslavia supuso el escenario de los primeros experimentos reales de gobernanza, en unas ocasiones protagonizados por la Unión Europea, en otras por Naciones Unidas.

Los comienzos tuvieron lugar con el establecimiento de administraciones a pequeña escala como UNTAES ${ }^{22}$ en Eslovenia Oriental (Croacia) en 1996, y la $\mathrm{EUAM}^{23}$ en la ciudad de Mostar

22. United Nations Transitional Administration for Eastern Slavonia (Administración de Transición de las Naciones Unidas en Eslovenia Oriental).

23. European Union Advisory Mission (Misión de Asesoramiento de la Unión Europea). 
(Bosnia Herzegovina) en 1994 (Stahn, 2008, p. 301), ambas con una duración prevista de dos años.

EUAM es una administración europea a nivel municipal, una continuación de aquellos experimentos históricos de internacionalización de pequeñas entidades territoriales pero con un nuevo formato, el de operación conjunta de los Estados miembros de la Unión Europea en el marco de la Política Exterior y de Seguridad Común (PESC). La EUAM es única en cuanto a estructura y diseño, enmarcada en los Acuerdos de Dayton. Mostar se convirtió en un área bajo la administración de la Unión Europea pero siguió siendo oficialmente parte de la Federación de Bosnia Herzegovina, por tanto era una administración dentro de una administración, un experimento de gobernanza internacional a nivel local que operaba bajo la estructura internacionalizada de los Acuerdos de Dayton. Fue establecida a través de un Memorandum of Understanding el 5 de julio de 1994 porque la Unión Europea carecía de la capacidad jurídica para la firma de un acuerdo que instaurara una administración internacional transitoria dadas las particularidades de la PESC.

La administración del distrito bosnio de Brcko también estuvo sujeta a la supervisión internacional a partir de 1997, bajo el Régimen de Supervisión Internacional (International Supervisory Regime) nombrado por la Oficina del Alto Representante. El propósito de las tres misiones era facilitar la reconciliación étnica y la reintegración pacífica tras los conflictos ar- mados. Estos primeros ejercicios se llevaron a cabo de acuerdo con las partes implicadas y gozaban de poderes ejecutivos limitados pero en ningún caso legislativos o judiciales (Stahn, 2001, p. 133).

UNTAES fue establecida para supervisar la devolución a Croacia de la última región controlada por los serbios en esta república. El acuerdo firmado por el gobierno croata y los líderes serbios locales, que era la base de la misión, solicitaba que el Consejo de Seguridad estableciera una administración para gobernar el territorio mientras era devuelto a Croacia. El Representante Especial estableció un régimen en que la autoridad internacional transitoria era la única con poder ejecutivo, sin necesidad de consentimiento por las partes o del Ilamado Consejo Transitorio. Sin embargo, a diferencia de UNMIK en Kosovo y UNTAET en Timor Oriental, en Croacia se Ilevaron a cabo pocas de las tareas administrativas y se permitió a los serbios administrar el territorio, anulando sus decisiones cuando se consideraba necesario. UNTAES puede compararse con la misión que Naciones Unidas llevó a cabo en Nueva Guinea Occidental, de corta duración y con un objetivo muy específico: la transición pacífica de Eslovenia Oriental del control serbio a la autoridad administrativa croata. Un solo administrador transitorio de la ONU mantuvo el control total sobre los componentes civil y militar de la operación, que se considera un éxito en la historia de las operaciones de paz con componentes de construcción del Estado (Stahn, 2001, 133). 


\section{A. La Oficina del Alto Representante en Bosnia Herzegovina}

La misión establecida en Bosnia Herzegovina (Office of the High Representative -OHR-) es una misión muy específica, de gran complejidad y no estrictamente dentro del sistema de OMP de Naciones Unidas. Se estableció en 1995 para vigilar la implementación de los aspectos civiles de los Acuerdos de Dayton, que pusieron fin a la guerra en Bosnia Herzegovina, pero a pesar de tener un rol de supervisión, la extensión de sus poderes no estuvo clara hasta que estos se ejercieron. La OHR es una institución internacional creada ad hoc para llevar a cabo la supervisión de los aspectos civiles de la implementación de los Acuerdos de Dayton, que pusieron fin a la guerra en Bosnia Herzegovina.

Tras la negociación de los Acuerdos de Dayton tuvo lugar en Londres una Conferencia para la Implementación de la Paz con el objeto de movilizar el apoyo de la comunidad internacional a dichos Acuerdos, y su resultado fue el establecimiento del Consejo de Implementación de la Paz (PIC). El PIC engloba 55 países y agencias que apoyan el proceso de paz, bien financieramente, bien militarmente aportando tropas a la Fuerza de Estabilización (SFOR, por sus siglas en inglés) o bien llevando a cabo operaciones o proyectos en el terreno. Existe asimismo un número variable de observadores. Desde la Conferencia de Londres, el PIC se ha reunido a nivel ministerial en diversas ocasiones para revisar los progresos del plan de paz y los objetivos del siguiente periodo. En Londres se creó también la Junta Directiva del PIC cuyo presidente es el
Alto Representante, brazo ejecutivo del PIC. La Junta ofrece orientación política al Alto Representante y cuenta con los embajadores de los países miembros en sus reuniones.

El trabajo de OHR en la vida política de Bosnia Herzegovina fue cambiando y desarrollándose con el tiempo, y el mandato evolucionó también. Las similitudes existentes con el papel de UNMIK en Kosovo, en cuanto administración directa, son muchas, pero la semejanza no está en el diseño ni en el marco jurídico original sino en la implementación que de hecho se llevó a cabo. El enfoque utilizado por la comunidad internacional en Bosnia Herzegovina, previsto por los Acuerdos de Dayton, no estipulaba la sustitución del gobierno del Estado. En este caso, se entendió que las circunstancias sobre el terreno obligaban a un cambio de estrategia que resultó en un papel central del Alto Representante, que extendió sus poderes, de mera supervisión, con acciones legislativas y ejecutivas con la justificación de superar la parálisis de las instituciones nacionales (Friedrich, 2005, p. 139).

La piedra de toque en la evolución de OHR fue la Conferencia del PIC en Bonn, que tuvo lugar en diciembre de 1997 y que requirió del Alto Representante que despidiera a los funcionarios públicos que incumplieran sus compromisos legales o los Acuerdos de Dayton, y que dictara las leyes que considerase necesarias si los órganos legislativos no lo hacían.

Bosnia Herzegovina ha sido efectivamente administrada por la Unión Europea desde que la 
OHR fue reformada en 2002 y se transfirieron mayores poderes a la Dirección de Integración Europea, estableciéndola como el órgano ejecutivo más importante del gobierno bosnio. Esto ha llevado a algunos autores a afirmar que Bosnia Herzegovina debería ser considerada el primer Estado indiscutible de la Unión Europea, donde la soberanía ha sido completa y efectivamente transferida a Bruselas.

Se argumenta que el legado de la construcción del Estado por actores externos en Bosnia Herzegovina ha creado una división entre poder y responsabilidad y que, aunque Bosnia Herzegovina es un Estado formalmente independiente, el país carece de existencia autónoma fuera de la asociación con la Unión Europea (Chandler, 2006, p. 45). En este sentido, el ejercicio de la construcción del Estado ha creado lo que se ha dado en Ilamar Estado fantasma, en el que la política interior es prácticamente ociosa dado que las decisiones políticas son tomadas por expertos extranjeros y los políticos locales rinden cuentas a la comunidad internacional, y no tanto a los ciudadanos a los que representan (Caplan, 2007, p. 113).

\section{B. La Administración de Naciones Unidas en Kosovo}

Existen características similares entre el rol desempeñado por Naciones Unidas en Bosnia Herzegovina y aquel que habría de desempeñar en Kosovo, pero la semejanza no radica tanto en el marco original como en la implementación real. De modo contrario a Kosovo, la comunidad internacional en Bosnia Herzegovina no previó el establecimiento de nada parecido a un gobierno soberano del Estado y fueron las circunstancias sobre el terreno las que requirieron un cambio de estrategia que desembocó en un extraordinario poder para el Alto Representante en Bosnia Herzegovina, comparable al del Representante Especial del Secretario General. El Alto Representante extendió su papel inicial de supervisor a través de actuaciones legislativas y ejecutivas que se fueron incrementando ante la parálisis que sufrían las instituciones nacionales. Es posible que la experiencia en Bosnia Herzegovina condicionase el posterior despliegue de UNMIK en Kosovo, operación a la que se adjudicó desde el principio un papel de largo alcance atribuyéndole todos los poderes del Estado.

UNMIK en Kosovo es la misión que supuso por primera vez la creación de un territorio completamente administrado por Naciones Unidas. Pendientes las negociaciones sobre su estatus definitivo, la soberanía de Kosovo descansaba técnicamente en Serbia, pero a todos los efectos prácticos, Naciones Unidas era soberano y ejerció, durante una década, casi todos los atributos de la soberanía en nombre del pueblo de Kosovo. Cuando el Consejo de Seguridad de la ONU, a través de la Resolución 1244, autorizó a establecer una presencia internacional de seguridad militar y otra civil, lo hizo explícitamente bajo el capítulo VII de la Carta de Naciones Unidas, que ofrece cobertura legal suficiente para el despliegue de una administración territorial. De este modo el estatus constitucional de Kosovo desde junio de 
1999 a febrero de 2008 descansa en la resolución mencionada.

La presencia internacional de seguridad se materializó en KFOR (siglas para Kosovo Force). Autorizada por la Resolución en paralelo a la presencia civil, goza de independencia respecto a esta, si bien ambas han de coordinarse y apoyarse sin que haya jerarquía entre ellas. La tarea primordial de KFOR consistía en evitar el surgimiento de nuevas hostilidades manteniendo el alto el fuego, vigilar la retirada y el no regreso de las fuerzas yugoslavas y serbias del territorio kosovar.

Con el establecimiento de UNMIK, la ONU intentó colmar los huecos que había dejado abiertos en otras misiones, como Somalia y Congo. En lugar de operar en un Estado sin ley, dio los pasos necesarios para restablecer la ley aplicable y las funciones judiciales básicas en el territorio administrado. Además, UNMIK asumió toda la autoridad normativa al principio de la misión, algo que la distingue de la OHR, en Bosnia Herzegovina. Son enormes las dimensiones de la autoridad y la responsabilidad de las que gozaba la administración internacional en Kosovo, encargada efectivamente de la construcción y el gobierno de un Estado. También parece necesario insistir en que los retos políticos de UNMIK no son únicamente los problemas que afectan los objetivos centrales de una operación de mantenimiento de la paz, esto es, mantener la estabilidad y la seguridad (figuras tradicionales de la primera y segunda generación de OMP), sino enfrentarse al problema de cómo gobernar y con qué objetivos.
Kosovo resultó devastado por el conflicto. De una población formada por 1.7 millones de habitantes, había 1.3 millones de desplazados. La aparente seguridad estaba envuelta en un estado de constante tensión. Además de la minoría serbia, Kosovo es el hogar de las minorías romaní, ashkali, egipcia, bosniaca, turca y gorani. Las relaciones entre albanokosovares y el resto de minorías discurrían, tras la intervención de la OTAN, en condiciones aún no normalizadas y las ciudades a menudo estaban divididas por líneas étnicas. La infraestructura básica, así como los servicios públicos estaban destruidos o inoperantes, la economía había quedado completamente colapsada (Tansey, 2009, pp. 110 y ss.).

La adquisición repentina (transferida por el mandato del Consejo de Seguridad) del poder y la acumulación de responsabilidades puso a prueba la capacidad de UNMIK y de sus estrategias de gobierno, marcadas por la práctica del ensayo-error. UNMIK fue desde el principio reacia a definir sus poderes como los de una autoridad pública estatal sujeta a los mecanismos de equilibrio y control de los poderes o a la revisión judicial (Stahn, 2008, p. 309).

Duro y expresivo es, en este sentido, el juicio del Defensor del Pueblo de Kosovo, en su Informe de 2002, dirigido al Representante Especial del Secretario General de Naciones Unidas:

UNMIK no está estructurada según principios democráticos, no funciona de acuerdo con el imperio de la ley y no respeta importantes 
normas de derechos humanos internacionales. Las gentes de Kosovo son privadas de sus derechos básicos y de sus libertades tres años después del final del conflicto por la misma entidad creada para garantizarlos. ${ }^{24}$

En la Ley UNMIK 1999/1, el Representante Especial perfiló que la autoridad conferida a UNMIK por medio de la Resolución 1244 incluía todo el poder legislativo y ejecutivo, así como la potestad de administrar el sistema judicial. Según esta norma el Representante Especial puede emitir actos legislativos directamente aplicables y decidir, por tanto, cuál es el derecho en Kosovo, pero esto no es todo, puede también nombrar y cesar a cualquier persona dentro de la administración y del poder judicial. El alcance de su autoridad es prácticamente ilimitado. El Representante Especial tuvo durante una década el control sobre el gobierno, el sistema jurídico y el poder judicial en Kosovo.

La concentración de poder en manos de esta administración transitoria de Naciones Unidas desvela una especie de dificultad estructural característica de estas intervenciones internacionales para garantizar el cumplimiento de algunas exigencias ineludibles y tradicionales de un Estado democrático de derecho. En cierto modo, estamos ante el viejo problema de la adecuación de los medios y los fines. ¿La finalidad del mantenimiento de la paz, de la instauración de instituciones democráticas y del respeto de los derechos humanos en estos te- rritorios exigen necesariamente medios -esto es, formas de gobernanza- excepcionales o al menos no demasiados escrupulosas con el cumplimiento de los imperativos que dimanan del imperio de la ley?

A pesar de la Resolución 1244 y los Acuerdos de Rambouillet, a pesar de los objetivos de imperio de la ley e instauración de instituciones democráticas, a pesar de todos los textos referentes al Estado de derecho, la concentración de los tres poderes del Estado en unas manos, las del Representante Especial, lejos de servir como un modelo democrático contribuye a que la administración de Naciones Unidas se asemeje a una gran simulación. Se simula el funcionamiento de un Estado de rasgos constitucionales, las instituciones democráticas y el imperio de la ley; se simula el control sobre los actores que realizan funciones gubernamentales; se simula la soberanía de Serbia; y se simula el autogobierno de Kosovo.

\section{EL CASO DE TIMOR ORIENTAL}

UNMIK se creó para ser una excepción, sin embargo, menos de cinco meses después de desplegarla se puso en marcha UNTAET en Timor Oriental. El territorio era una antigua coIonia portuguesa que había sido gobernada por Indonesia desde 1975, pero la soberanía indonesia no era aceptada por la población en general, ni tuvo reconocimiento internacional

24. Ombudsperson Institution in Kosovo, “Second Annual Report 2001-2002. Addressed to Mr. Michael Steiner Special Representative of the Secretary General of the United Nations", de 10 de julio de 2002, p. 1. 
suficiente. Tras el referéndum celebrado sobre la independencia, en que los timorenses votaron abrumadoramente por la secesión, se produjo una intensa campaña de violencia que desplazó a la mayoría de la población y que finalizó con la intervención de una fuerza militar de mantenimiento de la paz (INTERFET), ${ }^{25}$ liderada por Australia. ${ }^{26}$

UNTAET y UNMIK pueden considerarse una nueva generación de OMP. En lo que respecta al art. 2.7 de la Carta de Naciones Unidas, que reza:

Ninguna disposición de esta Carta autorizará a las Naciones Unidas a intervenir en los asuntos que son esencialmente de la jurisdicción interna de los Estados, ni obligará a los Miembros a someter dichos asuntos a procedimientos de arreglo conforme a la presente Carta; pero este principio no se opone a la aplicación de las medidas coercitivas prescritas en el Capítulo VII,

parece claro que son (ambas misiones), cuanto menos, audaces, y muestran una "nueva confianza de la Organización en sus capacidades en materia de construcción del Estado" (Benzing, 2005, p. 298).

Como en el caso de Kosovo, Naciones Unidas encontró en Timor Oriental la destrucción masiva de infraestructuras, cientos de miles de refugiados, y vacío político. La solución a este escenario fue la creación de una administración internacional transitoria (UNTAET), que tres años después fue transformada en misión de asistencia, siendo devuelta oficialmente la soberanía a las autoridades locales (Gorjão, 2002, p. 315). En este sentido dista mucho del caso de Kosovo, donde Naciones Unidas sigue insistiendo en que UNMIK, que tiene hoy día solo una presencia simbólica en el territorio, se resiste a reconocer la independencia de Kosovo y mantiene que el país se encuentra, catorce años más tarde, todavía bajo la autoridad de la Resolución 1244, que autorizaba la participación de Naciones Unidas.

Ambos proyectos son a menudo calificados como absolutamente novedosos. Sin duda son inusuales y, en muchos aspectos, únicos. Pero si nos preguntamos por qué Naciones Unidas se ha embarcado en estas misiones debemos verlas en el contexto expuesto a lo largo de este artículo, acompañadas de aquellas que tuvieron lugar cuando existía la Sociedad de Naciones.

El derecho internacional tradicional no proporciona las herramientas adecuadas para abordar las situaciones posconflicto en las que los Estados no pueden ya garantizar el bienestar o la seguridad de su población. En particular, no resuelve cuál es exactamente el papel que pueden desempeñar las organizaciones inter-

25. International Force for East Timor (Fuerza Internacional para Timor Oriental).

26. Aprobada por el Consejo de Seguridad en Resolución del Consejo de Seguridad 1264, de 15 de septiembre de 1999. 
nacionales o los terceros Estados ni cuáles son los límites que dichos Estados u organizaciones han de respetar de modo que, en ocasiones, resulta complejo distinguir lo que se considera la participación de la organización internacional en un territorio, de su ocupación de este. Uno de los sistemas jurídicos internacionales existentes que limita los poderes del ocupante son las normas de derecho internacional humanitario en casos de ocupación bélica. Este sistema de normas se encuentra en los artículos 42 a 56 del Convenio de La Haya de 1907, 27 a 34 y 47 a 78 del IV Convenio de Ginebra y su Protocolo Adicional I, así como en el derecho internacional consuetudinario, pero no ofrecen un régimen jurídico que aborde los problemas específicos de las situaciones que suceden al conflicto. Esto puede deberse a que estas normas tienen el objeto de cubrir un periodo de transición que dura hasta la reorganización del gobierno del Estado ocupado y encontrar el justo equilibrio entre los intereses de seguridad de la potencia ocupante y la población ocupada, preservando el statu quo precedente en la medida de lo posible. La ocupación, solo en principio, no legitima la introducción de cambios políticos, incluso si son necesarios para el paso del totalitarismo a la democracia y, por tanto, la erradicación de las causas del conflicto. A pesar de sus dificultades, la aplicación por analogía de las normas de derecho humanitario sobre ocupación a la situación en la cual una organización internacional asume el control gubernamental de un territorio es una cuestión ampliamente debatida (Wolfrum, 2005, pp. 3-5).
En Timor Oriental se escogió un formato muy similar al de Kosovo y se dio a la misión toda la responsabilidad de administrar el territorio. Pero, ya en el momento de ser creadas existe una diferencia esencial entre las misiones de Kosovo y Timor Oriental: mientras UNTAET fue establecida por el Consejo de Seguridad con el fin de administrar el territorio hasta que Timor Oriental lograra la independencia el 20 de mayo de 2002, UNMIK se estableció en Kosovo sin saber cuál iba a ser el destino de la antigua provincia ni cuándo finalizaría la misión.

Nunca hubo duda sobre cuál era el objetivo político de la administración internacional transitoria en Timor Oriental, donde una clara mayoría de la población pudo decidir a favor de su independencia en un proceso acordado por todas las partes implicadas. Pero a pesar de tener un objetivo claro, la forma de llegar a él no gozaba de un consenso tan generalizado (Chopra, 2000). UNTAET operó en un ambiente político relativamente favorable que le concedía un grado de aceptación poco corriente entre las administraciones internacionales transitorias. En el momento que se estableció, los integracionistas de la línea dura habían huido ya a Indonesia y UNTERFET se había asegurado de que ni ellos ni sus aliados en el ejército indonesio estuvieran en condiciones de representar una amenaza. Además de esto, la inmensa mayoría de la población consideraba la intervención de la ONU como esencialmente positiva, aquellos con menos benevolente consideración la veían como un interregno necesario que debía preceder a la independencia. Cuando se desplegó la misión, a pesar de que el país estaba devasta- 
do por la guerra, el proceso político que debía llevarse a cabo no era la adjudicación del territorio entre facciones enfrentadas, dado que esta difícil tarea ya había sido llevada a cabo por la misión política precedente, UNAMET, que se encargó de supervisar la consulta popular y sus resultados en agosto de 1999. UNTAET tenía ante sí una labor política relativamente sencilla ajustada a una agenda y con el objetivo incontestable de preparar al país para la independencia (Benzing, 2005, p. 299).

Se ha señalado que el pequeño tamaño de Timor Oriental y su incontrovertido futuro, así como la ausencia de cualquier conflicto interno de relevancia durante la administración de la ONU, hicieron de este un caso simple de administración territorial. Se puede añadir el dato de que la población de Timor Oriental era y es bastante homogénea y no está dividida por tensiones étnicas y sociales como la de Kosovo, y desde el principio dio la bienvenida a la Organización como garante de la independencia, la paz y la seguridad. Pero no conviene, a pesar de esto, catalogar a UNTAET como un caso fácil: la reconstrucción de un territorio y su preparación para la independencia y el autogobierno en poco tiempo (treinta meses), con una población sin experiencia democrática previa y teniendo que hacer frente a la ausencia de instituciones propias no es un asunto baladí. UNTAET ha sido, y aún es, objeto de severas críticas respecto al cumplimiento de su mandato (Benzing, 2005, p. 299).

Los elementos estructurales/institucionales del caso de UNTAET, asevera Anthony Goldsto- ne, son los siguientes: la presión para poner en marcha una misión para abordar la emergencia humanitaria y el vacío administrativo tras el referéndum permitió solamente un planeamiento superficial y rápido de esta. En esta situación era necesario valorar el logro de objetivos a corto plazo, a expensas del logro de capacidades institucionales y construcción democrática a largo plazo. La situación se agravó con la decisión de transferir la autoridad de la operación no al Departamento de Asuntos Políticos (-DPA- que llevaba años dedicado a esta zona mientras fue responsable de UNAMET) sino al Departamento de Misiones de Mantenimiento de la Paz (DPKO), que estaba atado por su reciente experiencia poniendo en marcha UNMIK, y por tanto pobremente equipado para tratar con toda una gama de circunstancias políticas que eran específicas de Timor Oriental. Una de estas circunstancias era que, a pesar de los pocos recursos que habían quedado en Timor para levantar un Estado moderno, existía un grupo independentista, el Consejo de Resistencia Timorense (CNRT) que, aunque no constituía un gobierno soberano, disfrutaba de un alto grado de legitimidad, es decir, Timor Oriental no era políticamente una terra nullius y tal vez podía haber sido objeto de una OMP del modelo tradicional (Goldstone, 2004, p. 88).

En el caso de UNTAET, y también en el de UNMIK, la transferencia progresiva de autoridad era parte del plan diseñado para que la población local adquiriese finalmente la responsabilidad de su propio gobierno. La frustración a este respecto de los timorenses parece ser uno 
de los factores clave que llevaron a la misión a sufrir las etapas más críticas. El propio Representante Especial, Sergio Vieira de Mello, atribuyó muchos de los defectos de la misión a los errores iniciales de planeamiento y reconoció el fallo de Naciones Unidas a la hora de compartir el poder sin inconvenientes y con rapidez, y de permitir que los timorenses participaran en la formulación de políticas y su desarrollo (Caplan, 2005, p. 119). También hay que destacar que la lentitud con la que se llevó a cabo el comienzo de la misión tuvo efectos muy duraderos, y no cabe duda que la falta de cohesión dentro de Naciones Unidas tanto en Nueva York como en Dili era constatable y dañina para su eficacia (Goldstone, 2004, p. 90).

En mayo de 2006 Timor Oriental solicitó a Portugal, Malasia, Australia y Nueva Zelanda el envío de tropas para restaurar el orden, justo un año después del abandono del país por parte de Naciones Unidas, y cuatro desde la independencia. La violencia de aquellos momentos se cobró 37 vidas y desplazó a 155.000 personas (Porter y Rab, 2011, p. 1).

Puede concluirse, con carácter general, que existen incoherencias conceptuales entre la construcción del Estado y el establecimiento de administraciones internacionales transitorias, que parecen erigirse y autoasumirse como verdaderos gobiernos capaces de abordar dilemas normativos de relevancia, adoptando decisiones sobre qué procesos y necesidades deben ser prioritarios. Tal vez este sea uno de los motivos por los que después de la creación de UNTAET, la Organización de Naciones Unidas no ha puesto en marcha misiones que lleven consigo la administración directa de territorios, por el contrario ha puesto en marcha operaciones "de bajo impacto", con métodos de construcción del Estado mucho menos intrusivos que los expuestos (Porter y Rab, 2011, p. 1).

\section{REFLEXIONES FINALES}

No entraña el mismo grado de dificultad, ni requiere las mismas estrategias y habilidades realizar propuestas o tratar de evitar la violencia, los conflictos o las amenazas a la paz internacional surgidas desde el final de la Guerra Fría, que desarrollar políticas y prácticas sobre el terreno para construir Estados viables. El resultado de las intervenciones de construcción del Estado, en general, no es alentador. A pesar de los esfuerzos por asimilar los errores y mejorar los resultados, son muchas las opiniones que apuntan a que no hay éxitos de los que aprender:

Muchas intervenciones han tenido que repetirse tras la reanudación de la violencia, como en Angola, Liberia, Haití, Somalia, Sierra Leona y Timor Oriental. Una tercera parte o más de los acuerdos negociados desde 1990 han fracasado al formar gobiernos capaces de mantener la paz. Muchos otros casos de construcción del Estado siguen en el limbo debido al miedo de los intervinientes a retirar las fuerzas militares internacionales, como en los despliegues de Chipre, Líbano, Bosnia Herzegovina, Kosovo y la República Democrática del Congo. Algunos analistas 
incluso llegan a afirmar que algunos casos de fracaso del Estado, como Somalia o Congo, son una consecuencia de las intervenciones de construcción del Estado. (Woodward, 2011, pp. 316-317).

A esto se suma un elemento que ha estado presente, o esto he pretendido, a lo largo de todas las páginas precedentes: el asunto de la fuente de legitimidad que sostiene a las OMP y a las administraciones internacionales. En tanto Naciones Unidas concibe la buena gobernanza como base para la legitimación democrática, en el caso de un territorio internacionalizado, la legitimidad solo puede estar basada en el ejercicio de los poderes públicos de un modo que obtenga el respaldo social. La habilidad de la administración internacional para generar legitimidad interna que no se tiene sino que ha de crearse, se apoya en buena medida en la provisión efectiva de servicios y bienes públicos y en su compatibilidad con las ideologías locales y el entorno cultural.

Una de las razones por las que las administraciones territoriales han recibido atención creciente en los últimos años, y numerosas críticas, es que el ejercicio de la autoridad política sobre territorios posconflicto parece estar en contradicción con las concepciones contemporáneas de lo que debe ser un gobierno legítimo. Mientras la legitimidad de los gobiernos nace de nociones de autodeterminación y democracia, las administraciones internacionales, mientras duran, niegan ambas cosas a las poblaciones que gobiernan. Este es, para algunos, el dilema principal de la construcción del Estado por parte de organizaciones internacionales.

Existen dos clases de legitimidad democrática: la legitimidad de origen, que se produce cuando el poder se legitima por ser expresión, más o menos directa, de la voluntad de aquellos en los que se ejerce. Y la legitimidad de ejercicio, que es aquella que descansa no en el origen sino en la forma de ejercicio del poder. Es evidente que en las misiones de construcción del Estado de Naciones Unidas falta la legitimidad de origen, que no puede lograrse porque, al menos hasta la fecha, ninguna población ha tenido la posibilidad de manifestar su aceptación o rechazo por ningún medio. Por tanto, estas operaciones solo pueden legitimarse por su ejercicio del poder, y por los valores y resultados que sean capaces de producir.

La práctica jurídica internacional muestra la existencia de un doble rasero en la concepción estructural de la legitimidad internacional de los actos de gobierno, no solo en el área de la legitimidad democrática, también en el ámbito legislativo. Cabría esperar que los actores internacionales estuvieran sujetos a obligaciones similares a las de los actores estatales pero han existido pocos esfuerzos para imponer mecanismos de control a las administraciones transitorias en su ejercicio de la autoridad pública. La práctica en el campo de la gobernanza de las misiones de Naciones Unidas ilustra que las instituciones internacionales de gobierno han sido tratadas como entidades operativas reguladas por las mismas leyes y principios que las organizaciones internacionales, en términos 
de privilegios e inmunidades, obligaciones jurídicas y distribución interna del poder. No han sido consideradas actores estatales vinculados por los dictados de las leyes locales, a pesar de que hayan ejercido funciones gubernamentales y actuado como un Estado sustituto.

La ONU se ha resistido a poner en marcha instituciones independientes que revisaran las actuaciones de sus administraciones transitorias. Los actos de los administradores han sido, en ocasiones, simplemente declarados inapelables y vinculantes para los actores estatales.

Esta falta de revisión y control parece explicarse en que las administraciones de la ONU se han considerado parte de un ordenamiento jurídico distinto y separado del ordenamiento doméstico. Se ha argumentado que los actos públicos de las entidades internacionales no forman parte de la jurisdicción de los tribunales del Estado en que se actúa porque no son actos derivados de una autoridad perteneciente al territorio de ese Estado, que se encuentra bajo administración internacional. Otro argumento es que los actos de las administraciones establecidas por el Consejo de Seguridad se benefician de la presunción de legalidad ligada a las resoluciones dictadas con base en el capítulo VII de la Carta de Naciones Unidas. El ámbito de revisión judicial de los actos de las administraciones transitorias es tan reducido que sus actos legislativos son definidos como el derecho supremo del territorio, por encima de la legislación nacional o local (Stahn, 2005, p. 6).
El establecimiento de un sistema jurídico y la reforma y fortaleza del poder judicial han sido centrales en las administraciones internacionales transitorias desde el final de la Guerra Fría. El ordenamiento jurídico es un elemento constitutivo de los Estados modernos y una condición esencial para el ejercicio de autoridad. El derecho define la localización y el alcance de la autoridad; sin él, el alcance de la autoridad del Estado frente a sus ciudadanos no está claro y el gobierno está caracterizado por la arbitrariedad y la falta de responsabilidad. Por tanto, un orden jurídico eficaz es necesario para el establecimiento de la autoridad soberana. La legitimidad del sistema jurídico depende de que refleje los objetivos y propósitos de una sociedad, de que la sociedad sea propietaria del ordenamiento, y de que se aplique de forma eficaz.

\section{Referencias}

1. Benzing, M. (2005). Midwifing a New State: The United Nations in East Timor. Max Planck Yearbook of United Nations Law, 9(1), 295-372.

2. Berdal, M. y Economides, S. (Edits.). (2007). United Nations Interventionism, 1991-2004. Cambridge: Cambridge University Press.

3. Bull, C. (2008). No Entry without Strategy. Building the Rule of Law under UN Transitional Administration. Tokyo: United Nations University Press. 
4. Caplan, R. (2005). International Governance of War-Torn Territories. Oxford: Oxford University Press.

5. Caplan, R. (2007). Who guards the guardians? International accountability in Bosnia. En A. Hehir y N. Robinson (Edits.), State-Building. Theory and Practice (págs. 107-124). Londres: Routledge.

6. Cardona Llorens, J. (2003). Las operaciones de Paz de las Naciones Unidas: ¿Hacia una revisión de sus principios fundamentales? En J. Cardona Llorens (Coord.), Cursos Euromediterráneos Bancaja de Derecho Internacional (Vol. VI). Valencia: Tirant lo Blanch.

7. Chandler, D. (2006). Empire in Denial: The Politics of State-Building. Londres: Pluto Press.

8. Chesterman, S. (2004). You, the people: The United Nations, Transitional Administration, and State Building. Oxford: Oxford University Press.

9. Chesterman, S. (2005). Transitional Administration, State Building and the United Nations. En S. Chesterman, M. Ignatieff y R. C. Thakur, Making States Work: State Failure and the Crisis of Governance. Nueva York: United Nations University Press.

10. Chopra, J. (2000). The UN's Kingdom of East Timor. Survival, 42(3), 27-40.
11. Hammarskjöld, D. (1961). Memoria anual del Secretario General sobre la labor de la Organización, 16 de junio de 1960 - 15 de junio de 1961. Doc. A/ 4800 y add. 1. disponible en: http://daccess-dds-ny.un.org/ doc/UNDOC/GEN/NL6/100/04/PDF/ NL610004.pdf?OpenElement

12. De Wet, E. (2004). The Direct Administration of Territories by the United Nations and its Member States in the Post Cold War Era: Legal Bases and Implications for $\mathrm{Na}$ tional Law. Max Planck Yearbook of United Nations Law, (8), 291-340.

13. De Wet, E. y Wood, M. (2011). Collective Security. En R. Wolfrum (Edit.), Max Planck Encyclopedia of Public International Law. Oxford: Oxford University Press.

14. Friedrich, J. (2005). UNMIK in Kosovo: Struggling with Uncertainty. Max Planck Yearbook of United Nations Law, 9(1), 225-293.

15. Goldstone, A. (2004). UNTAET with Hindsight: The Peculiarities of Politics in an Incomplete State. Global Governance, 10(1), 83-98.

16. Gorjão, P. (2002). The Legacy and Lessons of the United Nations Transitional Administration in East Timor. Contemporary Southeast Asia, 24(2), 313-336.

17. Gray, C. (2008). The Charter Limitations on the Use of Force. Theory and Practice. En V. Lowe, A. Roberts, J. Welsh y D. Zaum. The 
United Nations Security Council and War (págs. 86-98). Oxford: Oxford University Press.

18. Kelsen, H. (1951). The Future of Collective Security. Revista Jurídica de la Universidad de Puerto Rico, XXI(2), 91.

19. Koskenmäki, R. (2005). Legitimacy and Accountability of International Administrations. Introductory Remarks. Trabajo presentado en el 'Workshop on Legitimacy and Accountability of International Administrations'. Ginebra: ESIL Research Forum.

20. Lowe, V., Roberts, A., Welsh, J. y Zaum, D. (2008). The United Nations Security Council and War. Oxford: Oxford University Press.

21. Malan, M. (1998). Peacekeeping in the new Millenium: Towards 'Fourth Generation' Peace Operations? African Security Review, 7(3), 13-20.

22. Malone, D. M. y Von Einsiedel, S. (2007). Haiti. En M. Berdal y S. Economices, (Edits.), United Nations Interventionism, 1991-2004. Cambridge: Cambridge University Press.

23. Matheson, M. (2001). United Nations Governance of Post-Conflict Societies. American Journal of International Law, 95(1), 76-85.

24. Mayall, J. (1996). The new interventionism, 1991-1994: United Nations experience in
Cambodia, former Yugoslavia and Somalia. Cambridge: Cambridge University Press.

25. Paris, R. y Sisk, T. D. (2007). Managing contradictions: The Inherent Dilemmas of Postwar Statebuilding. Nueva York: International Peace Academy.

26. Porter, D. y Rab, H. (2011). Timor-Leste's Recovery from the 2006 Crisis: Some Lessons. Background Note for the World Development Report 2011. The World Bank.

27. Roehner, N. (2010). Mission Intrusiveness as Peacebuilders' Leverage in Post-Conflict Democratization Processes. Trabajo presentado a la SGIR 7th Pan-European Conference on IR, 9 a 11 de septiembre de 2010. Estocolmo.

28. Sarooshi, D. (2008). The Security Council's Authorisation of Regional Arrangements to Use Force: The Case of NATO. En V. Lowe, A. Roberts, J. Welsh y D. Zaum (Edits.), United Nations Security Council and War (págs. 226-247). Oxford: Oxford University Press.

29. Stahn, C. (2001). The United Nations Transitional Administrations in Kosovo and East Timor. A First Analysis. Max Planck Yearbook of United Nations Law, 5, 105-183.

30. Stahn, C. (2005). Governance beyond the State: Issues of Legitimacy in International Territorial Administration. International Organizations Law Review, 1(2), 9-56. 
31. Stahn, C. (2008). The Law and Practice of International Territorial Administration: Versailles to Iraq and Beyond. Cambridge: Cambridge University Press.

32. Tansey, O. (2009). Regime-Building: Democratization and International Administration. Oxford: Oxford University Press.

33. Thakur, R. C. y Schnabel, A. (2001). United Nations Peacekeeping Operations: Ad Hoc Missions, Permanent Engagement. Nueva York: United Nations University Press.
34. Thullen, G. (1964). Problems of the Trusteeship System: A Study of Political Behavior in the United Nations. Genève: Librairie Droz.

35. Wolfrum, R. (2005). International Administration in Post-Conflict Situations by the United Nations and Other International Actors. Max Planck Yearbook of United Nations Law, 9(1), 649-696.

36. Woodward, S. L. (2011). Varieties of StateBuilding in the Balkans: A case for Shifting Focus. Berghof Handbook in Conflict Transformation, 2, 315-335. 